\title{
Using the chemical composition of otoliths to evaluate the nursery role of estuaries for English sole Pleuronectes vetulus populations
}

\author{
Jennifer A. Brown* \\ Department of Ecology and Evolutionary Biology, University of California, Santa Cruz, California 95064, USA \\ Present address: 47 Rio Vista Avenue, Oakland, California 94611, USA
}

\begin{abstract}
Juvenile English sole Pleuronectes vetulus were collected from estuaries and shallow, sandy, coastal habitats along the central California coast between 1996 and 2000, and adult English sole were collected from the Monterey Bay region in 2001 and 2002. The chemical composition of (1) whole juvenile otoliths and (2) the juvenile portion of adult otoliths was determined using inductivelycoupled plasma mass spectrometry (ICPMS). The concentration of Sr and Li in juvenile otoliths consistently differed between fish collected from estuarine and coastal habitats. Linear discriminantfunction analysis (LDFA) based on the Sr and Li content of juvenile otoliths was used to assign juvenile and adult fish to either the estuarine or coastal habitat group. Juveniles were assigned to the habitat type where they were captured with an accuracy of $77 \%$ for the 'All Sites' model and $82 \%$ for the 'Monterey Bay' model. The proportion of adult fish that were assigned to the estuarine habitat group was estimated to range between 45 and $57 \%$ depending on the model used. This level of estuarine contribution to adult English sole populations is much higher than would be expected based on the relative area of estuarine and sandy coastal habitats in central California. These results indicate that estuarine habitats are an important source of recruits for adult flatfish populations, and that conservation of estuaries may help maintain high levels of recruitment to harvested populations in central California.
\end{abstract}

KEY WORDS: Nursery habitat · Estuary $\cdot$ Open coast $\cdot$ Pleuronectes vetulus $\cdot$ Otolith $\cdot$ Chemical composition $\cdot \mathrm{Sr} \cdot \mathrm{Li} \cdot$ Central California

Resale or republication not permitted without written consent of the publisher

\section{INTRODUCTION}

Many coastal fish species have juvenile and adult life stages that occupy spatially separated habitats (reviewed by Gillanders et al. 2003). The juveniles often recruit to nearshore habitats, where they reside for months to years before migrating to offshore habitats to join the adult population. In addition, juveniles of many species with this life-history pattern recruit to more than 1 type of nearshore habitat, and these different habitats are likely to vary in quality (Heck et al. 2003, Minello et al. 2003). The highest-quality juvenile habitats are often referred to as 'nursery' habitats. Recently, the definition of a nursery habitat was clarified by Beck et al. (2001): 'A habitat is a nursery for juveniles of a particular species if its contribution per unit area to the production of individuals that recruit to adult populations is greater, on average, than production from other habitats in which juveniles occur.' Determining which juvenile habitats are functioning as nursery habitats is important to both understanding the ecological roles of the different juvenile habitats and managing harvested fish populations and coastal resources. Identification of nursery habitats is particularly important when some of the nearshore habitats used by juvenile fish are vulnerable to degradation or loss.

Determining which juvenile habitats are contributing more individuals to adult populations requires identifying the juvenile habitats in which the adults 
once lived. One way to determine prior residence of adult fish is to manually tag fish in all the alternative juvenile habitats and, subsequently, recover these tagged individuals as adults. However, this method is logistically difficult to implement because the small size of juveniles and the high rate of juvenile mortality necessitate a large number of individuals being tagged to get meaningful results. An alternative method to manual tagging requires that juveniles incorporate markers (e.g. elements, isotopes) characteristic of and specific to the habitat in which they reside. Such natural 'habitat tags' that allow differentiation of individuals from different juvenile habitats have been found in the calcified structures of many different marine organisms, including coral skeletons, bivalve shells, marine mammal teeth, invertebrate statoliths, and fish otoliths (Campana \& Thorrold 2001).

Chemically-based habitat tags incorporated within otoliths are particularly useful tools for determining prior residence of fish for 3 reasons. First, the deposition rate of trace elements into otolith material (aragonite in a protein matrix) can be influenced by environmental factors (e.g. water temperature, salinity, trace-metal abundance in the water) and physiological factors (e.g. growth rate, stress, ontogenic stage) that may differ between habitats (Campana 1999). Therefore, juvenile habitats with different environmental conditions may produce fish with otoliths that differ in their chemical composition. Second, otoliths are metabolically inert (Campana \& Neilson 1985), which results in the permanent retention of the habitat tag. Third, because otoliths grow continuously and contain daily and annual banding patterns, they can be used as long-term chronological recorders of environmental conditions (Campana \& Thorrold 2001). Hence, the environmental history of a fish at a specific time period in the past can be determined by analyzing the chemical composition of the portion of the otolith that corresponds to that specific time period.

Differences in the chemical composition of whole otoliths have been used to identify individuals with different dispersal histories (Swearer et al. 1999) or migratory patterns (Secor et al. 2001) and to differentiate individuals from different stocks (Campana et al. 1995, 2000), estuarine/riverine systems (Milton et al. 1997, Thorrold et al. 1998a,b, Gillanders \& Kingsford 2000, Gillanders 2002b), or nearshore habitats, including rocky reef and estuary (Gillanders \& Kingsford 1996) and open coast and estuary (Yamashita et al. 2000, Forrester \& Swearer 2002). Analysis of the chemical composition of the otolith along a transect from the center to edge (i.e. covering the ontogeny of an individual) has been used to determine timing of migrations, annulus (annual band) formation and other lifehistory events (Toole et al. 1993, Halden et al. 2000,
Secor \& Rooker 2000). In addition, analysis of only the juvenile portion of adult otoliths has allowed researchers to hindcast the juvenile habitat type from which adult fish originated (Gillanders \& Kingsford 1996, Yamashita et al. 2000, Thorrold et al. 2001, Forrester \& Swearer 2002, Gillanders 2002a, Patterson et al. 2004).

This study investigated the utility of using naturally occurring habitat tags in the otoliths of English sole Pleuronectes vetulus to determine the proportion of the adult population that recruited from 2 alternative juvenile habitats - estuaries and shallow coastal sandy habitats. The English sole is a commercially harvested species abundant along the Pacific coast of North America (Starr et al. 1998, Sampson \& Al-Jufaily 1999). Juveniles recruit to estuaries or shallow sandy habitats along the open coast in the spring and early summer. In the fall, juveniles leave the nearshore habitats and move into progressively deeper water where they join the adult population offshore (Starr et al. 1998). I have shown (Brown, in press) that a distinguishable chemical habitat tag exists in the otoliths of juvenile English sole and speckled sanddab Citharichthys stigmaeus collected from estuarine and coastal habitats along the central California coast. The purpose of the present study was to: (1) characterize the habitat tag in juvenile English sole collected from estuarine and coastal habitats, (2) determine if this chemical habitat tag was present in adult English sole collected in Monterey Bay by analyzing the portion of the adult otolith that was deposited when the fish was a juvenile, and (3) determine the proportion of the adults that originated from estuarine habitats. Determining the proportion of the adults that recruited from estuarine habitats would give insight into whether estuarine habitats are functioning as nurseries for the English sole population in central California.

\section{MATERIALS AND METHODS}

Collection of samples. The juvenile English sole used to characterize the juvenile habitat tag were collected between May and September from 7 estuaries and 11 coastal sites along a $500 \mathrm{~km}$ portion of the California coast (Fig. 1). This area encompassed most, if not all, of the likely source-habitats of adult English sole in central California (Jow 1969). All sites were sampled in 1999 and 2000, but due to logistical constraints, only a subset of these sites was sampled in 1998 (Table 1). English sole collected from Elkhorn Slough in 1996 and 1997 (by Dave Lindquist, Moss Landing Marine Laboratory) were also included in the analysis to increase the sample size of estuarine fish collected in the Monterey Bay region. Coastal juve- 
niles were collected by otter trawl and estuarine juveniles were collected using a combination of otter trawl and beach seine. Adult English sole were collected in the Monterey Bay region (Fig. 1) at 3 different times: on research cruises in June and July of 2001 and from a commercial processor in May 2002 (Table 1). Fish were kept on ice or frozen until dissection. They were measured (mm total length) and sagittal otoliths were removed, cleaned of adhering tissue, and stored dry in plastic vials.

Preparation of juvenile otoliths. When available, between 10 and 15 juveniles site ${ }^{-1} \mathrm{yr}^{-1}$ were selected for analysis (Table 1). Individuals were selected to span the size range collected at each site. In cases where fewer than 10 fish had been collected, all individuals were analyzed. The right sagittal otolith from each fish was transferred to acid-cleaned Eppendorf microcentrifuge tubes, weighed $( \pm 0.01 \mathrm{mg})$ and left to soak for

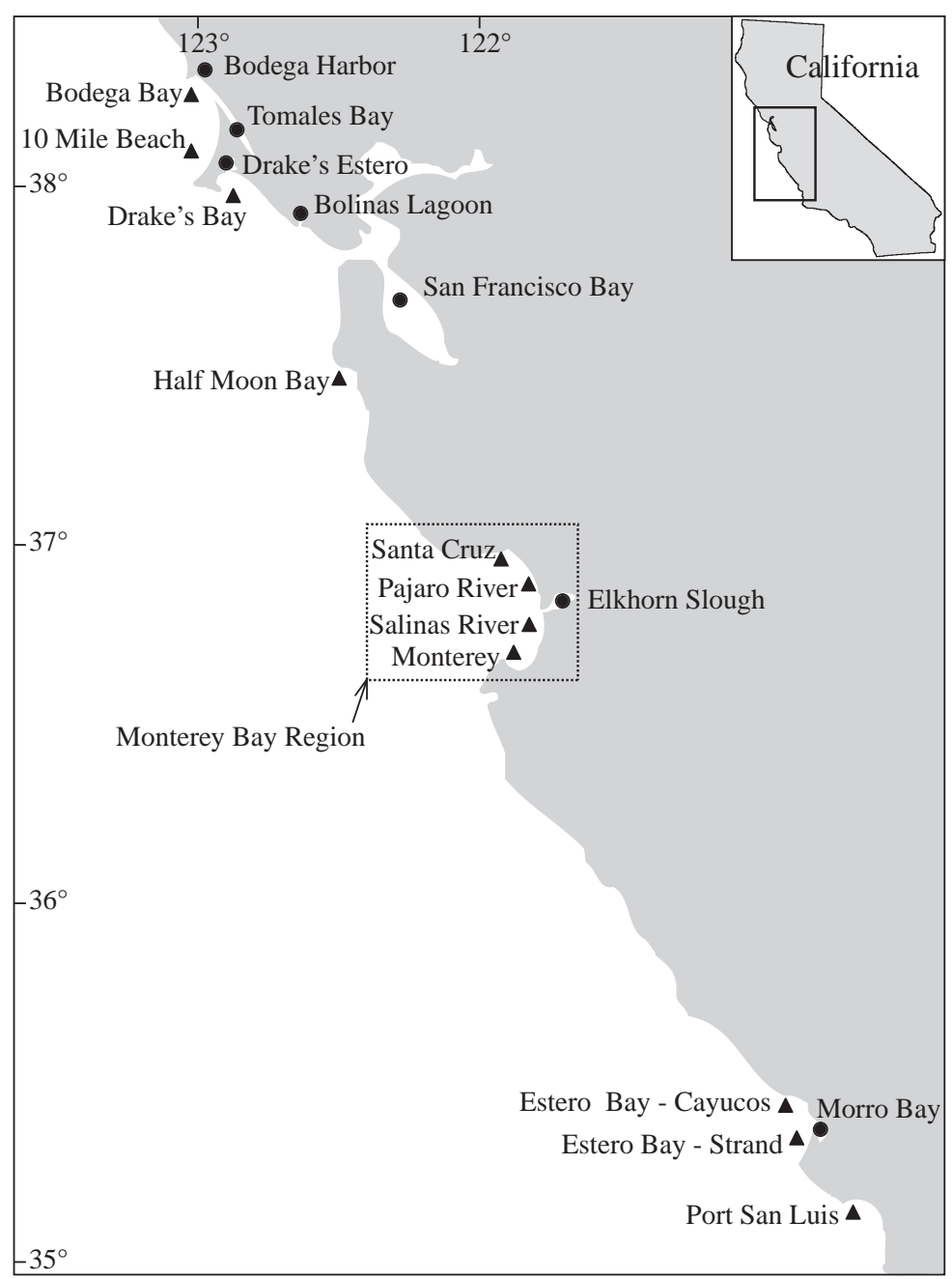

Fig. 1. California (inset), showing open coast $(\boldsymbol{\Delta})$ and estuary $(\bullet)$ sites from which juvenile English sole were collected. All adults examined in this study were collected from Monterey Bay region (boxed area)
$6 \mathrm{~h}$ in $30 \%$ Suprapur (EM Scientific) $\mathrm{H}_{2} \mathrm{O}_{2}$ to remove organic material. Otoliths were then double-rinsed in Milli-Q water, triple-washed in dilute acid $(0.01 \mathrm{~N}$ $\mathrm{HNO}_{3}$ ) to remove surface contaminants, and doublerinsed again in Milli-Q water. Otoliths were transferred to $4 \mathrm{ml}$ Nalgene (high density polyethylene) bottles and dissolved in $1 \% \mathrm{HNO}_{3}$ at a ratio of $2 \mathrm{ml}$ of solution $\mathrm{mg}^{-1}$ otolith (final concentration of $\sim 200 \mathrm{ppm}$ Ca). Following weighing, all sample handling was performed in a High Efficiency Particulate Air class 100 laminar-flow hood. Unless otherwise stated, all $\mathrm{HNO}_{3}$ used was trace-metal grade (Fischer Scientific). Initially, plasticware used in sample preparation and analysis was acid-leached in $2 \mathrm{~N} \mathrm{HNO}_{3}$ for $72 \mathrm{~h}$, rinsed with Milli-Q water, and dried in the laminar-flow hood prior to use. However, this procedure was changed to include a longer acid-leaching process $(7 \mathrm{~d}$ each in heated $3 \mathrm{~N} \mathrm{HCl}$ and $\mathrm{HNO}_{3}$ ) after continued leaching of $\mathrm{Mg}$ from the $4 \mathrm{ml}$ Nalgene bottles was detected in procedural blanks (for a more detailed cleaning methodology see Brown 2003).

Preparation of adult otoliths. Otoliths from adult fish of many species contain an annual banding pattern - wide opaque summer bands alternating with narrow translucent winter bands when viewed under reflected light (Campana 2001). Annual banding has been found in the otoliths and interopercular bones of adult English sole, with the first annulus (translucent band) formation beginning at the end of the first summer/fall growth period (Smith \& Nitsos 1969, Van Cleve \& El-Sayed 1969). To determine the birth year of the adult English sole collected in this study, the right sagittal otolith of each adult was viewed under a dissecting microscope using reflected light and a black background. Age (yr) was determined by counting translucent bands and using the date of collection to back-calculate birth year. The annual banding pattern was more easily discerned in some individuals than in others; only adults with a clear banding pattern that indicated a birth year corresponding to the years in which juveniles were collected (1998, 1999 and 2000) were selected for analysis $(\mathrm{n}=67)$.

For the purpose of chemical analysis, the right sagittal otolith was embedded in epoxy (Epoxicure, Beuhler) and the juvenile core extracted. Juvenile cores consisted of all material deposited during the larval and juvenile growth seasons before formation of the first annulus. Cores were extracted by 


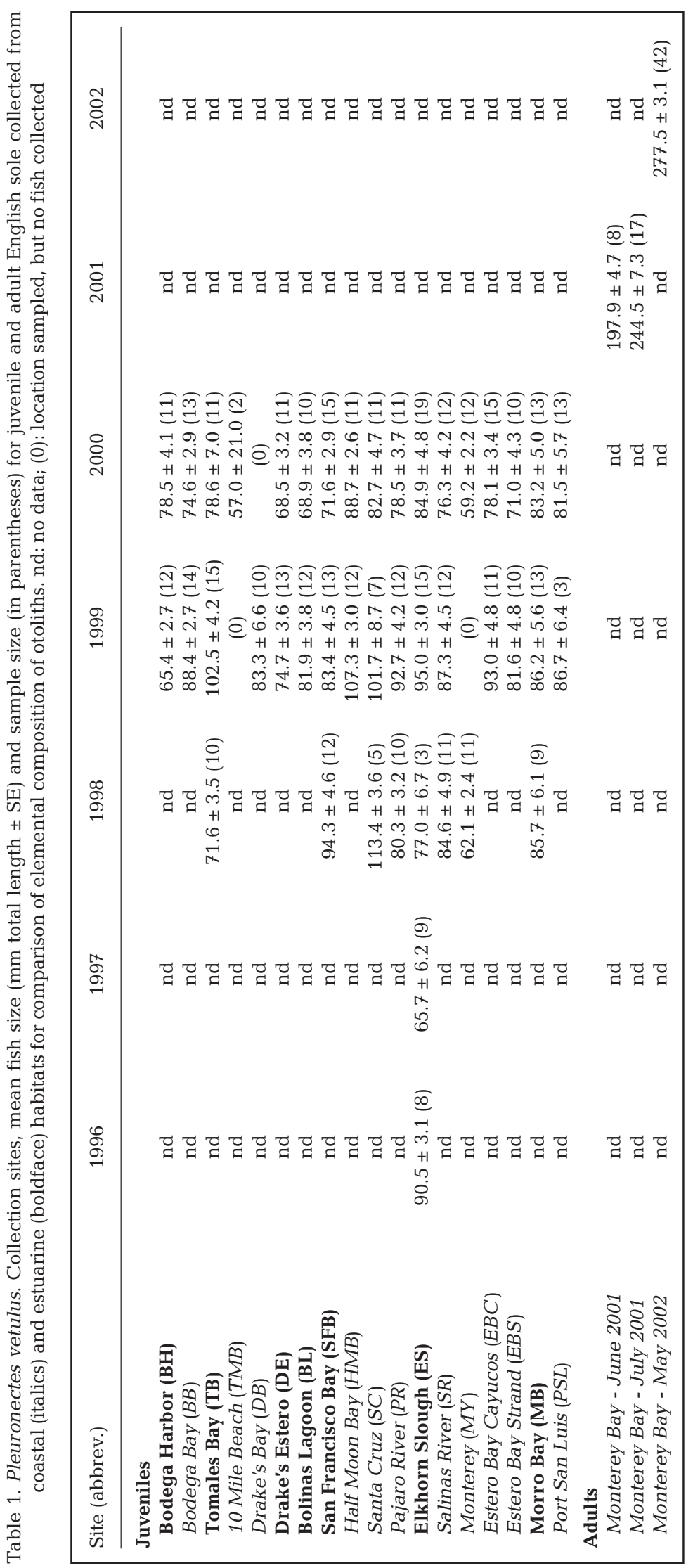

cutting away the surrounding otolith material in a multi-step process (Fig. 2). The first 2 steps used a low-speed isomet saw fitted with diamond blades and run with Milli-Q water as the lubricant. First, the rostrum and postrostrum were removed by cutting with a single blade through the first annulus. Double blades fitted with spacers were then used to cut a thin section (approximately $300 \mu \mathrm{m}$ thick) along the sagittal plane. The thin section was attached to a microscope slide using double-sided tape and then a microdrill was used to free the juvenile core from the surrounding otolith material by drilling along the first annulus. The thin sections were fragile and frequently cracked during the drilling process. All available pieces of each core were removed from the tape, placed in an acid-cleaned Eppendorf tube and rinsed twice with Milli-Q water to remove dust contamination from the drilling process. Cores were then weighed and cleaned following the same procedure used for juvenile otoliths. Based on a comparison of whole otoliths and otoliths cut into pieces using a diamond saw, Dove et al. (1996) concluded that a similar procedure of rinsing

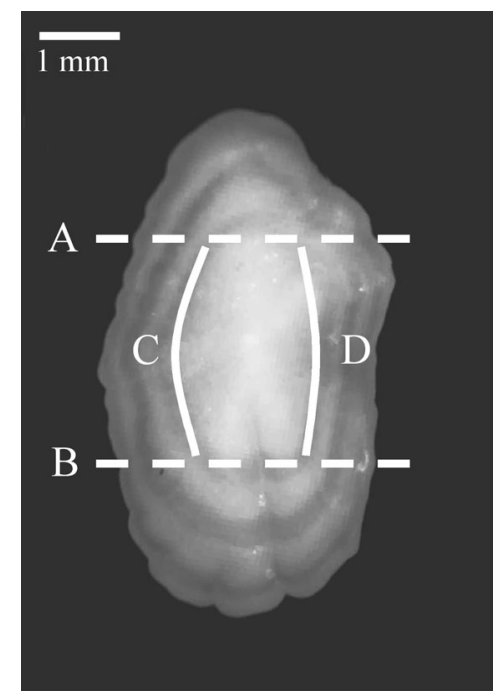

Fig. 2. Pleuronectes vetulus. Juvenile core isolated from otoliths of adult English sole in a multistep process. An isomet saw was used to remove edge material from the rostrum and post-rostrum along Cuts $\mathrm{A}$ and $\mathrm{B}$, and to make a thin section approximately $300 \mu \mathrm{m}$ thick along the sagittal plane (plane of this page). A microdrill was used to remove right and left sides from the thin section by drilling along translucent band corresponding to 1st winter (Paths C and D) 
otolith pieces with a combination of Milli-Q water and dilute acid removed any contamination acquired during the sawing process. The cores were left to dry over night in a laminar-flow hood.

Sample analysis. A procedural blank was prepared in the same manner as samples, but no otolith was present. The procedural blank was compared to the system blank to determine if contamination occurred during processing. System blanks were made from the same acid used for sample dissolution. System blanks were run every 4 samples and were used for blank corrections and to determine limits of detection. A spike standard was prepared by gravimetrically spiking a Ca standard solution with appropriate concentrations of $\mathrm{Li}, \mathrm{Mg}, \mathrm{Mn}, \mathrm{Ni}, \mathrm{Cu}, \mathrm{Zn}, \mathrm{Sr}, \mathrm{Ba}, \mathrm{Pb}$ to match the typical elemental composition of the otoliths. The spike standard was analyzed every 4 samples to track, and correct for, instrument drift. A consistency standard (a bulk digestion of flatfish otoliths) was analyzed at the beginning of each run of 24 samples to assess consistency of measurements over multiple runs within a day and over multiple days. All measurements were carried out on a Finnigan MAT Element sectorfield inductively coupled plasma mass spectrometer (ICPMS).

Initially, 10 elements $\left({ }^{7} \mathrm{Li},{ }^{25} \mathrm{Mg},{ }^{43} \mathrm{Ca},{ }^{55} \mathrm{Mn},{ }^{62} \mathrm{Ni}\right.$, ${ }^{63} \mathrm{Cu},{ }^{66} \mathrm{Zn},{ }^{87} \mathrm{Sr},{ }^{138} \mathrm{Ba},{ }^{208} \mathrm{~Pb}$ ) were chosen for study based on preliminary analysis of the composition of juvenile flatfish otoliths. The limits of detection of each element were calculated for each run as 3 times the standard deviation of the system blank, and were applied to blank corrected intensities. $\mathrm{Ni}_{1} \mathrm{Cu}, \mathrm{Zn}$, and $\mathrm{Pb}$ intensities were frequently at or below detection limits, and were therefore removed from the analysis; $\mathrm{Mg}$ was removed due to possible contamination from $4 \mathrm{ml}$ bottles; $\mathrm{Li}, \mathrm{Mn}, \mathrm{Sr}$, and Ba were consistently above detection limits and could be used for statistical analysis. Element: $\mathrm{Ca}^{43}$ ratios were determined from blankcorrected intensities using the spiked standard to correct for instrumental mass discrimination (following Rosenthal et al. 1999). Estimates of precision (\% relative standard deviation) based on repeated analysis of the otolith consistency standard were determined for each elemental ratio to be: ${ }^{7} \mathrm{Li}:{ }^{43} \mathrm{Ca}=2.62 \%,{ }^{55} \mathrm{Mn}:{ }^{43} \mathrm{Ca}$ $=1.17 \%{ }^{87} \mathrm{Sr}:{ }^{43} \mathrm{Ca}=1.15 \%,{ }^{138} \mathrm{Ba}:{ }^{43} \mathrm{Ca}=1.49 \%(\mathrm{n}=16)$.

In a related investigation of the spatial and temporal patterns in element concentrations in the otoliths of these juvenile English sole, I found that $\mathrm{Sr}$ and Li concentrations differed between estuarine and coastal habitats and that these differences were consistent over the 3 yr studied (1998 to 2000) (Brown, in press). Although $\mathrm{Ba}$ and $\mathrm{Mn}$ also showed significant habitat differences, these differences were only present in some years. Because the adults used in this study were born over the $3 \mathrm{yr}$ in which juveniles were collected, only the elements ( $\mathrm{Sr}$ and Li) that showed temporal stability in the chemical tag were included in statistical analysis.

Analysis of data from juveniles. Data from each element was checked for univariate normality and homogeneity of variances (following Quinn \& Keough 2002). Sr was normally distributed after $\log _{10}$-transformation; Li was normally distributed without transformation. To ensure that differences in otolith size ( $\approx$ fish size) among samples did not confound any spatial patterns in elemental composition, the effect of otolith weight (OW) on element ratio was examined. A significant relationship was found for $\mathrm{Li}$ (Fig. $3 ; \mathrm{Li}=-0.314 \mathrm{OW}+$ $6.939 ; \mathrm{r}^{2}=0.172, \mathrm{p}<0.001$ ), but not for Sr. Hence, Li values were detrended using a 2 -step process: (1) the slope of the regression line was used to estimate a $\mathrm{Li}$ value corresponding to an otolith weight of $7.0 \mathrm{mg}$ (an approximate 'end-of-season' otolith weight; see below); and (2) for each sample, the specific residual from the regression relationship was added to the estimated $\mathrm{Li}$ value. This procedure produced a distribution of sample Li values that were unaffected by otolith weight. By detrending Li values to an end-of-season otolith weight, the resulting statistical models could be used to classify adults using their otolith cores, which contained material deposited during the entire juvenile growth season. Using the relationship between otolith weight (OW) and total length (TL) for juvenile and subadult English sole $(\sqrt{\mathrm{OW}}=0.021 \mathrm{TL}-0.249$, $\left.r^{2}=0.88, p<0.001\right)$, I calculated that an otolith weight of $7.0 \mathrm{mg}$ corresponded to a fish size of $140 \mathrm{~mm}$ TL.

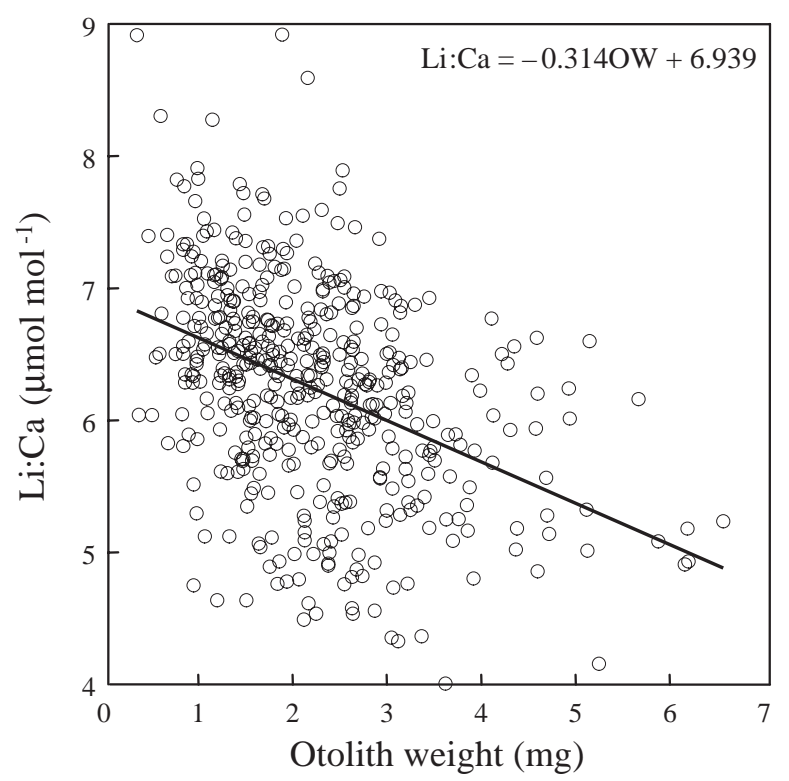

Fig. 3. Pleuronectes vetulus. Relationship between otolith weight (OW, mg) and Li:Ca in right sagittal otoliths of juveniles $\left(r^{2}=0.172, p<0.001\right)$ 
This end-of-season size was selected because juveniles larger than $140 \mathrm{~mm}$ are rarely encountered in estuarine habitats (summarized by Shi et al. 1997), and a first annulus begins to form in the interopercular bones of English sole that are approximately $135 \mathrm{~mm}$ (Smith \& Nitsos 1969).

I created 2 different juvenile classification models based on 2 types of movement patterns observed by Jow (1969), who found that most adult English sole tagged in California were non-migratory-they were re-captured near the release area. However, a few individuals exhibited migrations along the coast. The All Sites model used juveniles collected from every site in the study area under the assumption that the adults, although collected in the Monterey Bay region, could have migrated to that region from juvenile habitats to the north or south. The 'Monterey Bay' classification model only included juveniles collected from sites in the Monterey Bay region under the assumption that the adults collected in Monterey Bay were likely to be non-migrants and had resided in that same region as juveniles.

For each model, linear discriminant-function analysis (LDFA) was used to classify juvenile fish as being either from estuarine or coastal habitats based on the $\mathrm{Sr}$ and $\mathrm{Li}$ concentrations in their otoliths. The classification accuracy of each discriminant function was determined by comparing the jackknife (leave-one-out)-predicted group membership to the actual group membership and calculating the percentage of individuals that were correctly classified. Assumptions of LDFA, including multivariate normality and homogeneity of variancecovariance matrices, were checked graphically using squared-Mahalanobis distance plots and by examining the spread of each group on the canonical variate axes (following Tabachnick \& Fidell 2001).

Adult classification. Juvenile cores isolated from adult otoliths were assigned to a habitat group using both the All Sites and Monterey Bay classification models. In each case, the default classification model used Li values that had been detrended to an end-ofseason size of $140 \mathrm{~mm}$ TL to classify the juvenile fish. To investigate the impact that selecting $140 \mathrm{~mm}$ as the end-of-season size may have had on the classification of adults, I also created classification functions using $\mathrm{Li}$ values detrended to 135 and $145 \mathrm{~mm}$ TL. These alternative classification models would not change the classification accuracy of the models for juvenile fish, but they could alter the assignment of adults to estuary and coastal habitat groups.

Edge contamination. Despite intense efforts to remove all material surrounding the juvenile cores (hereafter referred to as edge material), it is possible that edge material was not completely removed from some cores during the sectioning and drilling process.
It is likely that edge material differed in chemical composition from core material. Thus, the presence of edge material in a core sample might cause inaccurate measurement of the chemical habitat tag in the cores. The most likely source of edge contamination is Age 1 material (first translucent and second opaque zones) adjacent to the core. However, this material could not be isolated for chemical analysis given the methodological constraints of the drilling process. Instead, all edge material that remained after drilling, consisting of a mixture of Age 1 and Age 2+ material (second translucent zone to edge of otolith) (depending on the age of the adult), was collected and analyzed for each of 13 adults. A paired $t$-test was used to determine if the core and edge material from a given individual differed in chemical composition and the magnitude of this difference. This estimate of the chemical composition of adult edges was used to correct for potential contamination of the cores.

To explore how contamination of cores with edge material might affect the classification of adults, 2 alternative scenarios were explored. The elemental concentrations measured in a core were adjusted assuming that either 10 or $25 \%$ of the mass of the core was actually edge material. To determine the 'true' chemical composition of the core material, the values of $\mathrm{Sr}$ and Li measured in the cores had to be adjusted to remove the effect of chemical contamination by edge material. The following equation was used to adjust the Li:Ca concentrations measured in each core under the assumption of $10 \%$ contamination:

$$
\mathrm{Li}_{10}=\frac{\mathrm{Li}_{\text {measured }}-\left(0.10 \cdot \mathrm{E}_{\text {mean }}\right)}{1-0.10}
$$

where $\mathrm{Li}_{10}$ is the adjusted concentration of core $\mathrm{Li}$, $\mathrm{Li}_{\text {measured }}$ is the Li concentration measured in the core, and $E_{\text {mean }}$ is the mean Li concentration of edge material $(\mathrm{n}=13)$. Similar equations were used to adjust $\mathrm{Li}$ values assuming $25 \%$ contamination, and to adjust Sr values assuming 10 and $25 \%$ contamination. The adjusted values represented the best estimate of the habitat tag in the juvenile core of each adult otolith. The core values, adjusted under both the 10 and $25 \%$ contamination scenarios, were classified as either estuarine or coastal using the default All Sites and Monterey Bay discriminant models (juvenile Li values detrended to $140 \mathrm{~mm} \mathrm{TL}$ ).

Correction of adult classification. Adults were assigned to estuarine or coastal habitat groups using discriminant models based on the chemical composition of the otoliths of juvenile estuarine and coastal fish. Although these models showed high classification accuracies for juvenile fish, in no case were they perfect (i.e. a classification accuracy of $100 \%$ ); that is, the discriminant models misclassified some juvenile fish. It 
is likely that errors also occurred when the discriminant models were used to assign adults to estuarine and coastal habitat groups. Under the assumption that a similar error rate occurred during assignment of juveniles and adults, I used the following equation to correct the number of adults assigned to the estuarine group to reflect the probabilities that (1) estuarine fish had been correctly classified as estuarine, and (2) estuarine fish had been incorrectly classified as coastal:

$$
\mathrm{N}[\text { adjusted, } \mathrm{e}]=\mathrm{p}[\mathrm{e}] \cdot \mathrm{N}[\mathrm{e}]+(1-\mathrm{p}[\mathrm{c}]) \cdot \mathrm{N}[\mathrm{c}]
$$

where $\mathrm{N}[\mathrm{e}]$ and $\mathrm{N}[\mathrm{c}]$ are the number of adults classified as estuarine and coastal by the classification model and $\mathrm{p}[\mathrm{e}]$ and $\mathrm{p}[\mathrm{c}]$ are the probabilities that an estuary fish and a coastal fish are correctly assigned by the classification model (based on the percentage of juveniles correctly classified in the model).

\section{RESULTS}

\section{Juvenile classification model}

In the All Sites model, estuarine fish had higher Sr $\left(0.29 \pm 0.003 \mathrm{mmol} \mathrm{mol}^{-1}\right)$ and lower Li $(4.34 \pm$ $\left.0.044 \mu \mathrm{mol} \mathrm{mol}{ }^{-1}\right)$ than coastal fish $(0.23 \pm 0.003 \mathrm{mmol}$ $\mathrm{mol}^{-1}$ and $5.09 \pm 0.037 \mu \mathrm{mol} \mathrm{mol}^{-1}$, respectively)
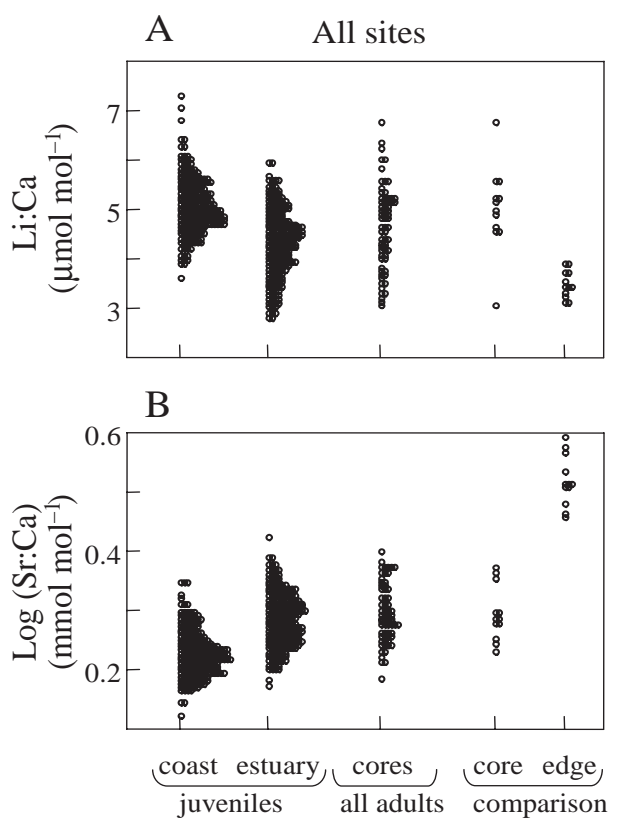

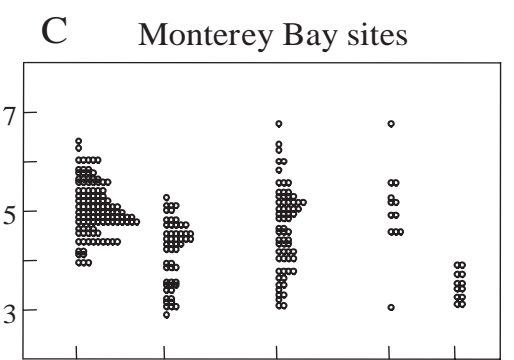

$\mathrm{D}$

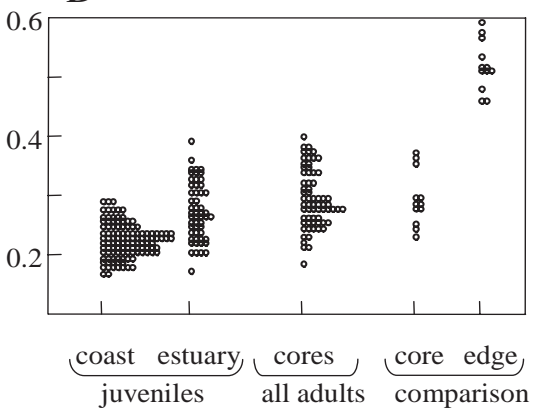

Fig. 4. Pleuronectes vetulus. Comparison of concentration of $\mathrm{Sr}$ and $\mathrm{Li}$ in otoliths of juveniles and adults. $\mathrm{Sr}$ and Li concentrations in otoliths of juvenile fish collected from open coast and estuary habitats are shown for all sites between Bodega and Port San Luis (A,B) and Monterey Bay sites only $(\mathrm{C}, \mathrm{D})$. Sr and $\mathrm{Li}$ concentration are shown for cores of all adult otoliths collected from Monterey Bay $(\mathrm{n}=67)$ and for a comparison of chemical composition of the cores and edges for a subset of these adults $(n=13)$
(Fig. 4). Given these differences in elemental concentrations, the All Sites discriminant function was able to accurately separate juvenile fish into estuarine and coastal groups (Wilk's $\lambda, F_{2,469}=161.6, \mathrm{p}<0.001$ ). Using the jackknife classification procedure on the sample of 472 fish, $81 \%$ of coastal fish $(\mathrm{n}=238)$ and $73 \%$ of estuarine fish $(\mathrm{n}=234)$ were correctly classified for an overall classification accuracy of $77 \%$.

Under the Monterey Bay model, the mean concentration of $\mathrm{Sr}$ and Li was $0.27\left( \pm 0.007 \mathrm{mmol} \mathrm{mol}^{-1}\right)$ and $4.17\left( \pm 0.098 \mu \mathrm{mol} \mathrm{mol}^{-1}\right)$ in estuarine fish and 0.23 $\left( \pm 0.003 \mathrm{mmol} \mathrm{mol}^{-1}\right)$ and $5.06\left( \pm 0.049 \mathrm{\mu mol} \mathrm{mol}^{-1}\right)$ in coastal fish (Fig. 4). The Monterey Bay discriminant function also was able to accurately separate juvenile fish into habitat groups (Wilk's $\lambda, F_{2,165}=62.5$, $\mathrm{p}<0.001$ ). Using the jackknife classification procedure on this reduced sample of 168 fish, $85 \%$ of coastal fish $(\mathrm{n}=114)$ and $74 \%$ of estuarine fish $(\mathrm{n}=54)$ were correctly classified for an overall classification accuracy of $82 \%$.

\section{Adult classification}

The concentration of $\mathrm{Sr}$ and Li measured in juvenile cores of adult otoliths was very similar to the $\mathrm{Sr}$ and Li concentrations found in otoliths from estuarine and coastal juveniles (Fig. 4). Under the default All Sites model, 47 adults were classified as estuarine and 20 were classified as coastal (Table 2). However, the default model had misclassified $19 \%$ of coastal juveniles and $27 \%$ of estuarine juveniles. Correcting for these errors in the classification model (Eq. 2) resulted in an estimate of 38 estuarine and 29 coastal adults; that is, $57 \%$ of the adult fish were estimated to have spent a portion of their juvenile period in estuarine habitats. This result was unchanged using Li values detrended to $135 \mathrm{~mm}$ (TL). Using Li values detrended to $145 \mathrm{~mm}$ resulted in a slightly lower estimate of the percentage of the adult population that came from estuaries $(52 \%)$.

The Monterey Bay classification model provided slightly lower estimates of estuarine residence. Under the default model, 43 adults were classified as estuarine and 24 were classified as coastal (Table 2). Correcting these values for error in the default classification model resulted in an estimate of 35 estuarine and 32 coastal 
Table 2. Pleuronectes vetulus. Number of adult English sole classified into either coast or estuary habitat group (n), number in the estuary group corrected (Eq. 2) for error in the juvenile classification model (n corrected), and resulting percentage in the estuary group (\% corrected) using discriminant functions derived from juveniles collected from (A) all sites between Bodega Bay and Port San Luis and (B) Monterey Bay only. Default classification model used Li values detrended to a juvenile size of $140 \mathrm{~mm}$ total length (TL); discriminant functions based on Li values detrended to 135 and 145 $\mathrm{mm}$ were also used to classify adults. The default model assumed no contamination of adult otolith cores with material from the otolith edge. Sr and $\mathrm{Li}$ (detrended to $140 \mathrm{~mm}$ ) values in cores were adjusted (Eq. 1) assuming $10 \%$ of core material was contaminated with edge material before classification

\begin{tabular}{|c|c|c|c|c|}
\hline \multirow{2}{*}{ Classification model } & \multirow{2}{*}{$\begin{array}{c}\text { Coast } \\
\mathrm{n}\end{array}$} & \multirow[b]{2}{*}{$\mathrm{n}$} & — Estuary & \multirow{2}{*}{$\%$ corrected } \\
\hline & & & n corrected & \\
\hline \multicolumn{5}{|l|}{ (A) All Sites } \\
\hline Default & 20 & 47 & 38 & 57 \\
\hline Li:Ca (135 mm TL) & 20 & 47 & 38 & 57 \\
\hline Li:Ca (145 mm TL) & 26 & 41 & 35 & 52 \\
\hline $10 \%$ contamination & 33 & 34 & 31 & 46 \\
\hline \multicolumn{5}{|l|}{ (B) Monterey Bay } \\
\hline Default & 24 & 43 & 35 & 53 \\
\hline Li:Ca (135 mm TL) & 20 & 47 & 38 & 56 \\
\hline Li:Ca (145 mm TL) & 29 & 38 & 32 & 48 \\
\hline $10 \%$ contamination & 33 & 34 & 30 & 45 \\
\hline
\end{tabular}

adults: $53 \%$ of the adults were estimated to have resided during a portion of their juvenile period in Elkhorn Slough, the only estuarine habitat located in the Monterey Bay region. Using Li values detrended to 135 and $145 \mathrm{~mm}$ resulted in estimates that 56 and $48 \%$ of the adults came from Elkhorn Slough (Table 2).

\section{Edge contamination}

The core and edge portions of adult otoliths differed significantly in their $\mathrm{Li}$ content (paired $t$-test, $\left.t_{12}=-5.621, \mathrm{p}<0.001\right)$. In general, Li was less abun-

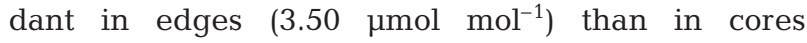
(4.97 $\mathrm{mmol} \mathrm{mol}^{-1}$ ) (Fig. 4). All but 2 adults showed similar decreases in Li content between the core and edge portions of their otoliths. The Li concentrations in edges was similar to the $\mathrm{Li}$ concentrations found in otoliths from estuarine juveniles (Fig. 4). Therefore, contamination of cores with edge material would decrease the Li values measured in some cores (particularly those with higher Li concentrations) and cause them to more closely resemble estuarine juveniles. However, contamination with edge material would not significantly alter Li values in cores with low Li concentrations. By adjusting the core values under the assumption of 10 or $25 \%$ contamination of the core mass with edge material, the Li concentration of cores with already high Li was increased. These elevated core values were within the range of Li values observed in juvenile otoliths under the $10 \%$ contamination sce- nario, but not under the $25 \%$ contamination scenario (Fig. 5). Therefore, a level of $25 \%$ contamination was considered unlikely based on adjusted Li values.

Cores and edges also differed significantly in their Sr content (paired t-test, $\left.t_{12}=13.40, \mathrm{p}<0.001\right)$. Sr was more abundant in edges $\left(0.522 \mathrm{mmol} \mathrm{mol}^{-1}\right)$ than in cores (0.298 mmol mol-1) (Fig. 4). All 13 adults analyzed showed similar increases in Sr content between the core and edge portion of the otolith. Sr concentrations in edges were well above the Sr concentrations measured in otoliths of juveniles from either estuarine or coastal habitats. Therefore, contamination of cores with edge material would elevate the true $\mathrm{Sr}$ values of cores, and make the cores more closely resemble estuarine juveniles. By adjusting the core values under the assumption of 10 or $25 \%$ contamination, the Sr value for all cores was decreased. The decreased core values were within the range of Sr values observed in juvenile otoliths under the $10 \%$ contamination scenario, but not under the $25 \%$ contamination scenario (Fig. 5). As with $\mathrm{Li}$, a level of $25 \%$ contamination of core mass was considered unlikely based on adjusted Sr values.

Given that the $10 \%$ contamination scenario appeared plausible, cores were reclassified with the default All Sites and Monterey Bay classification models (Li detrended to $140 \mathrm{~mm}$ TL) using Li and Sr values adjusted for $10 \%$ contamination. Under the default All Sites model, and after correction for assignment error in that model, 31 adults were classified as estuarine and 36 were classified as coastal (Table 2); that is, $46 \%$ of the adult fish were estimated to have spent time in the estuarine habitats. Similar estimates were found using the default Monterey Bay model: $45 \%$ of the adult fish were estimated to have spent a portion of their juvenile period in the Elkhorn Slough estuary (Table 2). Thus, removing the effect of possible contamination of the cores by edge material resulted in a slight decrease in the number of adults classified as having originated from estuarine habitats.

\section{DISCUSSION}

\section{Are estuaries nursery habitats for English sole in central California?}

The use of a chemical tag to discriminate fish living in different habitats requires that the otoliths of fish collected from those habitats differ in their chemical 

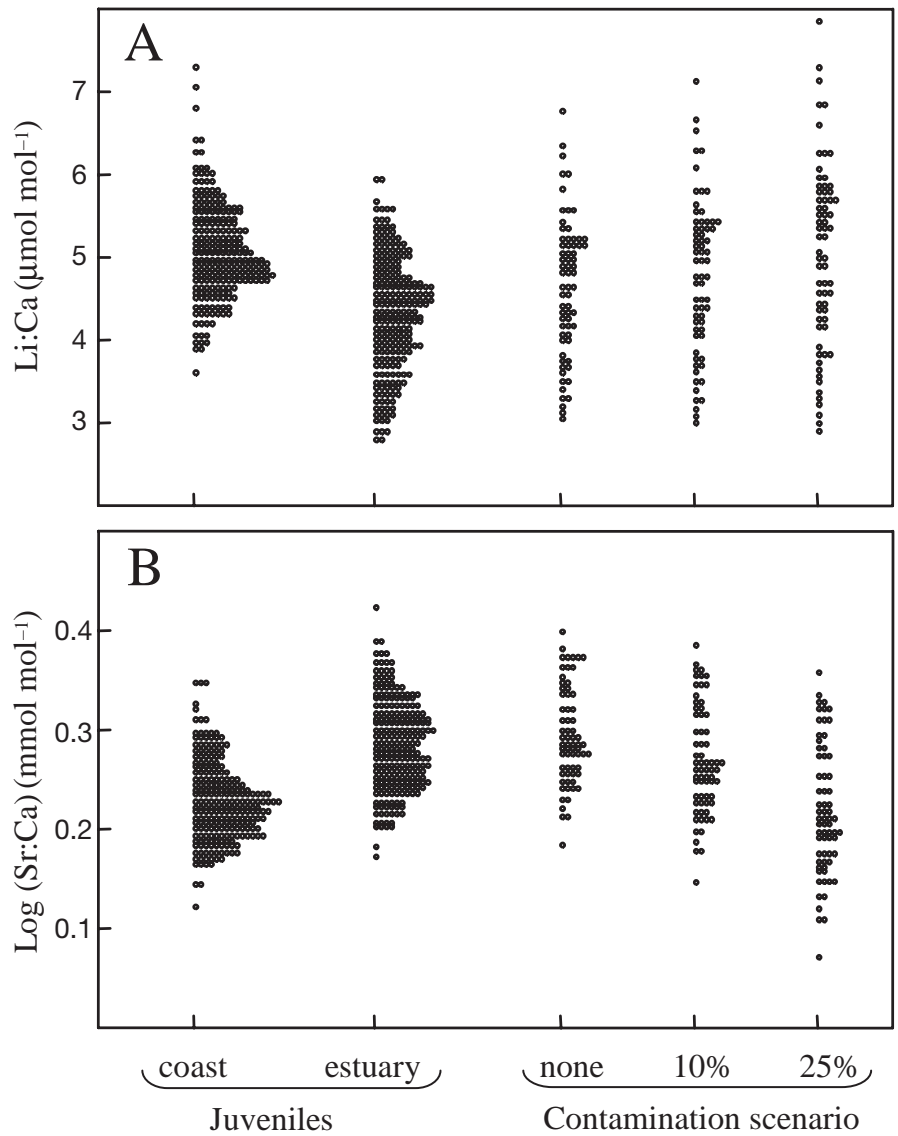

Fig. 5. Pleuronectes vetulus. Concentration of (A) Li and (B) Sr in otoliths from juveniles and adults. Element concentrations are shown for juveniles collected from coastal and estuarine habitats and for cores of otoliths from adults collected from Monterey Bay. Core values are shown under 3 contamination scenarios: no contamination; $10 \%$ of core contaminated with edge material; $25 \%$ of core contaminated with edge material. Core values were adjusted to remove effects of contamination using Eq. (1)

composition. In addition, the chemical habitat tag may be used to identify adult fish that once resided in the different juvenile habitats if the tag meets 2 criteria (summarized in Campana et al. 2000). First, the habitat tag should be consistent over the time period during which habitat assignment is to be made. Second, the habitat tag must be characterized using individuals collected from all possible source habitats for the adult population under study. My results indicate that juvenile English sole living in estuarine and coastal habitats had otoliths that differed significantly in their chemical composition. The habitat tag was found to be present and consistently distinguishable in juveniles collected over a $3 \mathrm{yr}$ period (1998 to 2000) — the time period during which the adult fish used in this study would have been living in the juvenile habitats. In addition, the habitat tag was consistent over the 2 spatial scales (All Sites and Monterey Bay) that encompassed the likely source-habitats of adults with alternate life histories: all sites in the study area could be sources of migratory adults whereas only sites in the Monterey Bay are the likely source of non-migrants. Thus, the chemical habitat tag was found to meet all criteria for use in identifying the juvenile habitats from which adult fish recruited.

The All Sites and Monterey Bay classification models produced very similar estimates of percentage of the adult population that resided in estuaries as juveniles: 46 to $57 \%$ and 45 to $56 \%$, respectively; thus, the estuarine contribution to the central California English sole population was estimated to be approximately $50 \%$, irrespective of the model used. Estuaries, however, comprise much less than $50 \%$ of the available juvenile habitat in central California. For example, in the Monterey Bay region, the intertidal and subtidal habitats of Elkhorn Slough (the only estuary in the region) cover approximately $11.8 \mathrm{~km}^{2}$, while suitable coastal habitat (sandy bottom between 10 and $30 \mathrm{~m}$ depth; Krygier \& Pearcy 1986) covers approximately $177 \mathrm{~km}^{2}$. Therefore, even though estuarine habitat comprises only about $6 \%$ of the available juvenile habitat, the estuary appears to be the source of approximately half of the adult fish collected in the region. This result suggests that estuarine habitats in central California are acting as nursery habitats by contrFibuting substantially more individuals per unit area to the adult English sole population than the adjacent coastal habitats (Beck et al. 2001).

The disproportionate contribution of 1 juvenile habitat to the adult population may be due to fish in that habitat having higher densities, higher growth rates, lower mortality, or more successful recruitment to the adult population (Beck et al. 2001). Past research on English sole along the west coast of North America has found evidence that estuaries can support higher densities (Krygier \& Pearcy 1986, Rogers et al. 1988, Gunderson et al. 1990) and faster growth rates (Krygier \& Pearcy 1986, Brown 2003) than coastal habitats. In addition, 1 study using parasites as a natural tag of estuarine residence concluded that the majority of adult English sole had recruited to the adult population from estuarine habitats (Olson \& Pratt 1973). These findings suggest that estuarine habitats may be producing more juvenile English sole because they support a higher density of faster-growing fish that successfully recruit to the adult population.

\section{Juvenile habitat tag}

The classification success of the discriminant models generated in this study was due to consistent differences in $\mathrm{Sr}: \mathrm{Ca}$ and Li:Ca ratios in the otoliths of estuar- 
ine and coastal fish; $\mathrm{Sr}$ :Ca was higher and Li:Ca was lower in estuarine habitats. A number of environmental and physiological factors (e.g. temperature, salinity and growth rate) can influence deposition of trace elements in otoliths. The estuarine habitats examined in this study are characterized (during the summer/fall juvenile growth season) by higher salinities, faster growth rates and warmer and more variable water temperatures than the surrounding coastal habitats (Broenkow 1977, Brown 2003). Thus, the pattern found in this study of elevated $\mathrm{Sr}$ :Ca in estuarine English sole may have been caused by $\mathrm{Sr}$ :Ca concentrations being positively correlated with any of these factors. Previous studies on various fish species have found $\mathrm{Sr}: \mathrm{Ca}$ to be positively correlated with temperature (Kalish 1989, Bath et al. 2000, Yamashita et al. 2000), salinity (Kalish 1990, Secor \& Rooker 2000) and growth rates (Yamashita et al. 2000). Alternatively, increased deposition of $\mathrm{Sr}$ in otoliths of estuarine English sole may be due to higher stress levels caused by the frequent and extreme fluctuations in water temperature and salinity in estuarine environments (Kalish 1992, Yamashita et al. 2000). Controlled laboratory experiments are needed to determine which of these factors may be responsible for the elevated $\mathrm{Sr}$ :Ca values in estuarine English sole.

Although multiple studies have found Li to be a useful element for differentiating habitat groups (Milton et al. 1997, Campana et al. 2000, Rooker et al. 2001, Gillanders 2002b, Gillanders \& Kingsford 2003), very little attention has been given to determining the environmental and physiological factors that effect $\mathrm{Li}$ incorporation into otoliths. Fluvial input from continents is one of the major sources of dissolved Li in coastal waters and the abundance of this element has been shown to be negatively correlated with salinity (Bruland 1983). A negative relationship between Li:Ca and salinity is consistent with the pattern found in this study of elevated Li:Ca values in the otoliths of coastal juveniles (estuaries in central California are hypersaline in summer months). The present study also found a significant negative relationship between otolith weight and $\mathrm{Li}: \mathrm{Ca}$, indicating that ontogenic processes influenced Li incorporation into otoliths. These results indicate that multiple factors may influence the deposition of $\mathrm{Li}$ in otoliths. This is an area that requires further study. Fortunately, it is not necessary to understand the mechanisms responsible for generating habitat-related differences in elemental concentrations to be able to use these chemical differences as habitat tags (Thorrold et al. 1998a).

The discriminant models, based on the habitatrelated differences in $\mathrm{Sr}: \mathrm{Ca}$ and $\mathrm{Li}: \mathrm{Ca}$, classified coastal juveniles with more accuracy than estuarine juveniles. One possible reason for lower classification accuracy for estuarine juveniles is that environmental conditions are more variable in estuaries than on the coast. Within an estuary, individual fishes can experience vastly different environmental conditions depending on their location within the estuary. For example, fishes that reside in the upper channels and mudflats of Elkhorn Slough will experience higher temperatures and salinities than those living near the mouth (Broenkow 1977). The variability in environmental conditions among the estuaries in this study is also quite large: some estuaries are small and shallow (Bolinas Lagoon), while others are large and deep (Drake's Estero); some receive large inputs of agricultural runoff (Elkhorn Slough), while others receive large amounts of industrial runoff (San Francisco Bay). In comparison, the coastal habitats in central California have fairly constant environmental conditions (Broenkow 1977, Brown 2003). Given the increased variability in environmental conditions in estuaries, the estuarine habitat tag is probably more variable and difficult to accurately classify than the coastal habitat tag.

Misclassification of some juveniles may have been caused by their movement into the collection habitat from an adjacent alternative habitat type. Depending on the timing of the move relative to the time of capture, the measured habitat tag might be either typical of the alternative habitat type or an intermediate value. This potential cause of misclassification was explored by examining posterior probabilities (i.e. the probability of assignment to each habitat group). A fish that had moved recently should have a low probability of assignment in the habitat from which it was collected and a high probability of assignment in the alternative habitat type. A few individuals were identified that fit the above profile and, thus, might have recently moved into the collection habitat. However, the majority of the fish that were misclassified had intermediate probabilities ( 0.40 to 0.60 ) of classification in either habitat group. This pattern of posterior probabilities could be caused by fish spending a significant amount of time in both juvenile habitats typeseither by moving frequently between habitats or by moving into the habitat of capture weeks to months prior to capture. In addition, a fish residing in an area with environmental conditions that were either atypical or intermediate in comparison to most estuarine and coastal habitats may have intermediate posterior probabilities. The current study could not differentiate between these alternative causes of misclassifications.

\section{Adult classification method}

To use chemical habitat tags to identify the juvenile habitats from which adult fish recruited, the chemical 
composition of the juvenile portion of the adult otoliths must be determined. In this study, the juvenile portion of adult otoliths was extracted by cutting away the surrounding otolith material and analyzing the chemical composition of the juvenile core with the same methods used on otoliths from juveniles. Gillanders \& Kingsford (1996) successfully used this core extraction method to differentiate adult blue groper Achoerodus viridis that had recruited from rocky reefs and estuaries. The core-extraction method appears to have been applied successfully in this study as well; the range of $\mathrm{Sr}: \mathrm{Ca}$ and Li:Ca values in the juvenile cores were similar to the range of $\mathrm{Sr}: \mathrm{Ca}$ and $\mathrm{Li}: \mathrm{Ca}$ values found in juvenile otoliths. Therefore, the discriminant functions based on the chemical composition of otoliths from estuarine and coastal juveniles could be used to classify adults as having recruited from either estuarine or coastal habitats.

Using the default All Sites and Monterey Bay classification models, I estimated that 57 and $53 \%$ of the adult fish had lived as juveniles in estuarine habitats, respectively. These percentages were determined by correcting the initial estimates generated by the classification models to account for errors in habitat assignment. Errors in habitat assignment had to be corrected for because the error rates were not equivalent for the 2 habitat groups; the model had a higher probability of mis-assigning a fish to the estuarine group than to the coastal group. The corrected percentages represented better estimates of true estuarine contribution than the initial values produced by the models, as long as the error rates in assignment were equal for juveniles and adults. Because the adults used in this study were living in the same habitats at the same time as the juveniles used to create the classification models, there was no obvious reason to doubt the validity of this assumption.

The default All Sites and Monterey Bay classification models used $\mathrm{Li}$ values for juveniles that were detrended to an end-of-season fish size of $140 \mathrm{~mm}$. The negative relationship between $\mathrm{Li}$ :Ca and otolith size ( $\approx$ fish size) had to be removed for 2 reasons. First, the habitat-related difference in $\mathrm{Li}$ :Ca values between estuarine and coastal fish would have been confounded by ontogenetic trend, and the classification accuracy of discriminant models would have been diminished. Second, the juvenile cores extracted from the adult otoliths contained material deposited over the entire juvenile growth season. Thus, Li:Ca values in cores are representative of $\mathrm{Li}: \mathrm{Ca}$ values found in the otoliths of large juveniles. If the classification model had not used Li values detrended to an end-of-season fish size, then the distribution of Li values in juvenile otoliths would not have overlapped the distribution of $\mathrm{Li}$ values in juvenile cores. Classification of adults would not have been possible if discriminant models had used raw Li:Ca values.

An end-of-season fish size of $140 \mathrm{~mm}$ TL was chosen as the default model for detrending Li:Ca values. Choosing an appropriate end-of-season size is important because it determines the mean of the Li distribution for juvenile fish and, thus, can affect the assignment of adults to habitat groups. Changing the end-ofseason fish size by $\pm 5 \mathrm{~mm}$ TL did alter the percentage of the adults that were assigned to estuarine and coastal habitat groups. However, the change was not substantial (i.e. $5 \%$ or less in either direction).

In the core-extraction method, which requires cutting away the surrounding otolith material, there was the potential for contamination of the core by edge material. Contamination can modify the habitat tag present in the cores if edge material has a different chemical composition than core material. Core material and edge material was found to have different $\mathrm{Sr}: \mathrm{Ca}$ and Li:Ca concentrations and, because edge material had higher Sr:Ca and lower Li:Ca, contamination may have led to the misclassification of some coastal fish and, thus, an over estimate of estuarine contribution. When adult fish were reclassified using core values adjusted for $10 \%$ contamination, the estimates of estuarine contribution were reduced to 46 and $45 \%$ for the default All Sites and Monterey Bay classification models. However, this was probably an extreme estimate of the impact of contamination on adult classification because it is unlikely that all cores were contaminated. In addition, the material that would have caused contamination (Age 1 material located immediately adjacent to the cores) may have been more similar in chemical composition to the core than the edge material that was analyzed in this study (a mixture of Age 1 and Age 2+ material). Therefore, the presence of edge material in extracted cores may not have had as large an influence on the chemical composition of cores as was assumed in the contamination model.

\section{CONCLUSIONS}

Chemical habitat tags in otoliths were used to assign juvenile English sole to a habitat group (estuarine or coastal) with an accuracy of $77 \%$ for the All Sites model and $82 \%$ for the Monterey Bay model. The proportion of adult fish that were assigned to the estuarine habitat group was estimated to range between 45 and $57 \%$, depending on the model used. This level of estuarine contribution to adult English sole populations is much higher than would be expected based on the relative area of estuarine and sandy coastal habitats in central California. Evidence for disproportionate con- 
tribution of estuarine habitats to adult flatfish populations has recently been found for 2 other flatfish species - stone flounder Platichthys bicoloratus in Sendai Bay, Japan (Yamashita et al. 2000), and California halibut Paralichthys californicus in southern California (Forrester \& Swearer 2002). These findings combined with those of the current study suggest that estuarine habitats may commonly function as nursery habitats for juvenile flatfishes. Many estuarine habitats in California, and around the globe, are vulnerable to loss or deterioration from a variety of processes, including erosion, pollution and urbanization. Conservation of these estuarine nursery habitats may be an important step in maintaining high levels of recruitment to harvested flatfish populations. To more fully determine the importance of estuarine habitats to the maintenance of English sole populations in California, the contribution of estuaries should be determined over larger spatial and temporal scales. Identifying the regions in which disproportionate contribution consistently occurs would help to determine which estuarine habitats should be targeted for protection.

Acknowledgements. Thanks to K. Crow, S. Forde, C. Hays, C. Phillis, L. Garske, I. Tetreault, J. Hie, K. Menard and others for helping with fish collections, and R. Baxter, C. Pattison, B. Hardy, and C. Roberts for providing samples from their monitoring programs. I am grateful to A. Birkhead for help with laboratory work and R. Franks for help with analyzing samples by ICPMS. P. Raimondi, M.Carr, C. Grimes, B. Gillanders and 2 anonymous reviewers provided useful comments on this manuscript. This research was supported by awards from the Achievement Rewards for College Scientists Foundation, Dr. Earl H. Myers and Ethel M. Myers Oceanographic and Marine Biology Trust, Sigma Delta Epsilon, Friends of the Long Marine Laboratory, Phi Beta Kappa, and the Estuarine Reserves Division, Office of Ocean and Coastal Resource Management, National Ocean Service, National Oceanic and Atmospheric Administration. This is contribution number 179 from PISCO, the Partnership for Interdisciplinary Studies of Coastal Oceans - a long-term ecological consortium funded by the David and Lucile Packard Foundation.

\section{LITERATURE CITED}

Bath GE, Thorrold SR, Jones CM, Campana SE, McLaren JW, Lam JWH (2000) Strontium and barium uptake in aragonitic otoliths of marine fish. Geochim Cosmochim Acta 64: 1705-1714

Beck MW, Heck KL Jr, Able KW, Childers DL and 9 others (2001) The identification, conservation, and management of estuarine and marine nurseries for fish and invertebrates. BioScience 51:633-641

Broenkow WW (1977) Water chemistry of Elkhorn Slough and Moss Landing harbor. In: Nybakken JW, Cailliet GM, Broenkow WW (eds) Ecological and hydrographic studies of Elkhorn Slough, Moss Landing harbor and nearshore coastal waters, July 1974 to June 1976. Moss Landing Marine Laboratories, Moss Landing, CA, p 388-465

Brown JA (2003) An evaluation of the nursery role of estuar- ies for flatfish populations in central California. PhD dissertation, University of California, Santa Cruz, CA

Brown JA (in press) Classification of juvenile flatfish to estuarine and coastal habitats based on the elemental composition of otoliths. Estuar Coast Shelf Sci

Bruland KW (1983) Trace elements in sea-water. In: Riley JP, Chester R (eds) Chemical oceanography. Academic Press, London, p 157-220

Campana SE (1999) Chemistry and composition of fish otoliths: pathways, mechanisms and applications. Mar Ecol Prog Ser 188:263-297

Campana SE (2001) Accuracy, precision and quality control in age determination, including a review of the use and abuse of age validation methods. J Fish Biol 59:197-242

Campana SE, Neilson JD (1985) Microstructure of fish otoliths. Can J Fish Aquat Sci 42:1014-1032

Campana SE, Thorrold SR (2001) Otoliths, increments, and elements: keys to a comprehensive understanding of fish populations? Can J Fish Aquat Sci 58:30-38

Campana SE, Gagne JA, McLaren JW (1995) Elemental fingerprinting of fish otoliths using ID-ICPMS. Mar Ecol Prog Ser 122:115-120

Campana SE, Chouinard GA, Hanson JM, Frechet A, Brattey $J$ (2000) Otolith elemental fingerprints as biological tracers of fish stocks. Fish Res 46:343-357

Dove SG, Gillanders BM, Kingsford MJ (1996) An investigation of chronological differences in the deposition of trace metals in the otoliths of two temperate reef fishes. J Exp Mar Biol Ecol 205:15-33

Forrester GE, Swearer SE (2002) Trace elements in otoliths indicate the use of open-coast versus bay nursery habitats by juvenile California halibut. Mar Ecol Prog Ser 241: 201-213

Gillanders BM (2002a) Connectivity between juvenile and adult fish populations: do adults remain near their recruitment estuaries? Mar Ecol Prog Ser 240:215-223

Gillanders BM (2002b) Temporal and spatial variability in elemental composition of otoliths: implications for determining stock identity and connectivity of populations. Can J Fish Aquat Sci 59:669-679

Gillanders BM, Kingsford MJ (1996) Elements in otoliths may elucidate the contribution of estuarine recruitment to sustaining coastal reef populations of a temperate reef fish. Mar Ecol Prog Ser 141:13-20

Gillanders BM, Kingsford MJ (2000) Elemental fingerprints of otoliths of fish may distinguish estuarine 'nursery' habitats. Mar Ecol Prog Ser 201:273-286

Gillanders BM, Kingsford MJ (2003) Spatial variation in elemental composition of otoliths of three species of fish (family Sparidae). Estuar Coast Shelf Sci 57:1049-1064

Gillanders BM, Able KW, Brown, JA, Eggleston DB, Sheridan PF (2003) Evidence of connectivity between juvenile and adult habitat for mobile marine fauna: an important component of nurseries. Mar Ecol Prog Ser 247:281-295

Gunderson DR, Armstrong DA, Shi YB, McConnaughey RA (1990) Patterns of estuarine use by juvenile English sole (Parophrys vetulus) and Dungeness crab (Cancer magister). Estuaries 13:59-71

Halden NM, Mejia SR, Babaluk JA, Reist JD, Kristofferson AH, Campbell JL, Teesdale WJ (2000) Oscillatory zinc distribution in Arctic char (Salvelinus alpinus) otoliths: the result of biology or environment? Fish Res 46:289-298

Heck KL Jr, Hays CG, Orth RJ (2003) A critical evaluation of the nursery role hypothesis for seagrass meadows. Mar Ecol Prog Ser 253:123-136

Jow T (1969) Results of English sole tagging off California. Pac Mar Fish Comm Bull 7:16-33 
Kalish JM (1989) Otolith microchemistry: validation of the effects of physiology, age and environment on otolith composition. J Exp Mar Biol Ecol 132:151-178

Kalish JM (1990) Use of otolith microchemistry to distinguish the progeny of sympatric anadromous and non-anadromous salmonids. Fish Bull 88:657-666

Kalish JM (1992) Formation of a stress-induced chemical check in fish otoliths. J Exp Mar Biol Ecol 162:265-277

Krygier EE, Pearcy WG (1986) The role of estuarine and offshore nursery areas for young English sole, Parophrys vetulus Girard, of Oregon. Fish Bull 84:119-132

Milton DA, Chenery SR, Farmer MJ, Blaber SJM (1997) Identifying the spawning estuaries of the tropical shad, terubok Tenualosa toli, using otolith microchemistry. Mar Ecol Prog Ser 153:283-291

Minello TJ, Able KW, Weinstein MP, Hays CG (2003) Salt marshes as nurseries for nekton: testing hypotheses on density, growth, and survival through meta-analysis. Mar Ecol Prog Ser 246:39-59

Olson RE, Pratt I (1973) Parasites as indicators of English sole (Parophrys vetulus) nursery grounds. Trans Am Fish Soc 2: 405-411

Patterson HM, McBride RS, Julien N (2004) Population structure of red drum (Sciaenops ocellatus) as determined by otolith chemistry. Mar Biol 144:855-862

Quinn GP, Keough MJ (2002) Experimental design and data analysis for biologists. University Press, Cambridge

Rogers CW, Gunderson DR, Armstrong DA (1988) Utilization of a Washington estuary by juvenile English sole, Parophrys vetulus. Fish Bull 86:823-831

Rooker JR, Secor DH, Zdanowicz VS, Itoh T (2001) Discrimination of northern bluefin tuna from nursery areas in the Pacific Ocean using otolith chemistry. Mar Ecol Prog Ser 218:275-282

Rosenthal Y, Field MP, Sherrell RM (1999) Precise determination of elemental/calcium ratios in calcareous samples using sector field inductively coupled plasma mass spectrometry. Anal Chem 71:3248-3253

Sampson DB, Al-Jufaily SM (1999) Geographic variation in the maturity and growth schedules of English sole along the US west coast. J Fish Biol 54:1-17

Secor DH, Rooker JR (2000) Is otolith strontium a useful scalar of life cycles in estuarine fishes? Fish Res 46:359-371

Editorial responsibility: Kenneth Heck (Contributing Editor), Dauphin Island, Alabama, USA
Secor DH, Rooker JR, Zlokovitz E, Zdanowicz VS (2001) Identification of riverine, estuarine, and coastal contingents of Hudson River striped bass based upon otolith elemental fingerprints. Mar Ecol Prog Ser 211:245-253

Shi Y, Gunderson DR, Sullivan PJ (1997) Growth and survival of 0+ English sole, Pleuronectes vetulus, in estuaries and adjacent nearshore waters off Washington. Fish Bull 95: 161-173

Smith JG, Nitsos RJ (1969) Age and growth studies of English sole, Parophrys vetulus, in Monterey Bay, California. Pac Mar Fish Comm Bull 7:74-79

Starr RM, Johnson KA, Laman EA, Cailliet GM (1998) Fishery resources of the Monterey Bay National Marine Sanctuary. Publ No. T-042. California Sea Grant College System, University of California, La Jolla, CA

Swearer SE, Caselle JE, Lea DW, Warner RR (1999) Larval retention and recruitment in an island population of a coral-reef fish. Nature 402:799-802

Tabachnick BG, Fidell LS (2001) Using multivariate statistics, 4th edn. Allyn \& Bacon, Needham Heights, MA

Thorrold SR, Jones CM, Campana SE, McLaren JW, Lam JWH (1998a) Trace element signatures in otoliths record natal river of juvenile American shad (Alosa sapidissima). Limnol Oceanogr 43:1826-1835

Thorrold SR, Jones CM, Swart PK, Targett TE (1998b) Accurate classification of juvenile weakfish Cynoscion regalis to estuarine nursery areas based on chemical signatures in otoliths. Mar Ecol Prog Ser 173:253-265

Thorrold SR, Latkoczy C, Swart PK, Jones CM (2001) Natal homing in a marine fish metapopulation. Science 291: 297-299

Toole CL, Markle DF, Harris PM (1993) Relationships between otolith microstructure, microchemistry, and early life history events in Dover sole, Microstomus pacificus. Fish Bull 91:732-753

Van Cleve R, El-Sayed SZ (1969) Age, growth, and productivity of an English sole (Parophrys vetulus) population in Puget Sound, Washington. Pac Mar Fish Comm Bull 7:52-71

Yamashita Y, Otake T, Yamada H (2000) Relative contributions from exposed inshore and estuarine nursery grounds to the recruitment of stone flounder, Platichthys bicoloratus, estimated using otolith $\mathrm{Sr}$ :Ca ratios. Fish Oceanogr 9:316-327

Submitted: March 25, 2004; Accepted: April 19, 2005

Proofs received from author(s): December 9, 2005 